\title{
Does eloquence subtype influence outcome following arteriovenous malformation surgery?
}

\author{
Justin R. Mascitelli, MD, ${ }^{1}$ Seungwon Yoon, BS, ${ }^{1}$ Tyler S. Cole, MD, ${ }^{1}$ Helen Kim, PhD, ${ }^{2}$ and \\ Michael T. Lawton, MD'
}

\begin{abstract}
1Department of Neurological Surgery, Barrow Neurological Institute, Phoenix, Arizona; and ${ }^{2}$ Center for Cerebrovascular Research, University of California, San Francisco, California
\end{abstract}

\begin{abstract}
OBJECTIVE Although numerous arteriovenous malformation (AVM) grading scales consider eloquence in risk assessment, none differentiate the types of eloquence. The purpose of this study was to determine if eloquence subtype affects clinical outcome.

METHODS This is a retrospective review of a prospectively collected clinical database of brain AVMs treated with microsurgery in the period from 1997 to 2017. The only inclusion criterion for this study was the presence of eloquence as defined by the Spetzler-Martin grading scale. Eloquence was preoperatively categorized by radiologists. Poor outcome was defined as a modified Rankin Scale (mRS) score 3-6, and worsening clinical status was defined as an increase in the mRS score at follow-up. Logistic regression analyses were performed.
\end{abstract}

RESULTS Two hundred forty-one patients ( $49.4 \%$ female; average age 33.9 years) with eloquent brain AVMs were included in this review. Of the AVMs (average size $2.7 \mathrm{~cm}$ ), $54.4 \%$ presented with hemorrhage, $46.2 \%$ had deep venous drainage, and $17.0 \%$ were diffuse. The most common eloquence type was sensorimotor (46.1\%), followed by visual (27.0\%) and language (22.0\%). Treatments included microsurgery alone (32.8\%), microsurgery plus embolization $(51.9 \%)$, microsurgery plus radiosurgery $(7.9 \%)$, and all three modalities $(7.5 \%)$. Motor mapping was used in $9 \%$ of sensorimotor AVM cases, and awake speech mapping was used in $13.2 \%$ of AVMs with language eloquence. Complications occurred in 24 patients (10\%). At the last follow-up (average 24 months), $71.4 \%$ of the patients were unchanged or improved and $16.6 \%$ had a poor outcome. There was no statistically significant difference in the baseline patient and AVM characteristics among the different subtypes of eloquence. In a multivariate analysis, in comparison to visual eloquence, both sensorimotor (OR 7.4, $p=0.004$ ) and language (OR 6.5, $p=0.015$ ) eloquence were associated with poor outcomes. Additionally, older age (OR 1.31, $p=0.016)$ and larger AVM size (OR 1.37, $p=0.034)$ were associated with poor outcomes.

CONCLUSIONS Unlike visual eloquence, sensorimotor and language eloquence were associated with worse clinical outcomes after the resection of eloquent AVMs. This nuance in AVM eloquence demands consideration before deciding on microsurgical intervention, especially when numerical grading systems produce a score near the borderline between operative and nonoperative management.

https://thejns.org/doi/abs/10.3171/2018.4.JNS18403

KEYWORDS arteriovenous malformation; brain eloquence; modified Rankin Scale; Spetzler-Martin grading system; Lawton-Young grading system; patient selection; risk prediction; vascular disorders

$\mathrm{B}$ RAIN arteriovenous malformations (AVMs) are a heterogeneous group of intracranial vascular lesions that have a number of different management paradigms, including observation, microsurgery, radiosurgery, embolization, and, most commonly, a combination of approaches. A number of different grading scales have been developed to better understand outcomes following microsurgery, ${ }^{16,25,26}$ radiosurgery, ${ }^{22,23,28,30}$ and embolization. ${ }^{4,5,19}$ The grading scales are used to understand treatment risk and to select patients for a given treatment. The most commonly used microsurgery grading scale is the Spetzler-Martin (SM) scale, ${ }^{25}$ which grades AVMs on a scale from 1 to 5 based on size, venous drainage, and eloquence.

ABBREVIATIONS AVM = arteriovenous malformation; fMRI = functional MRI; LED = lesion-to-eloquence distance; mRS = modified Rankin Scale; MSI = magnetic source imaging; $S M=$ Spetzler-Martin. 

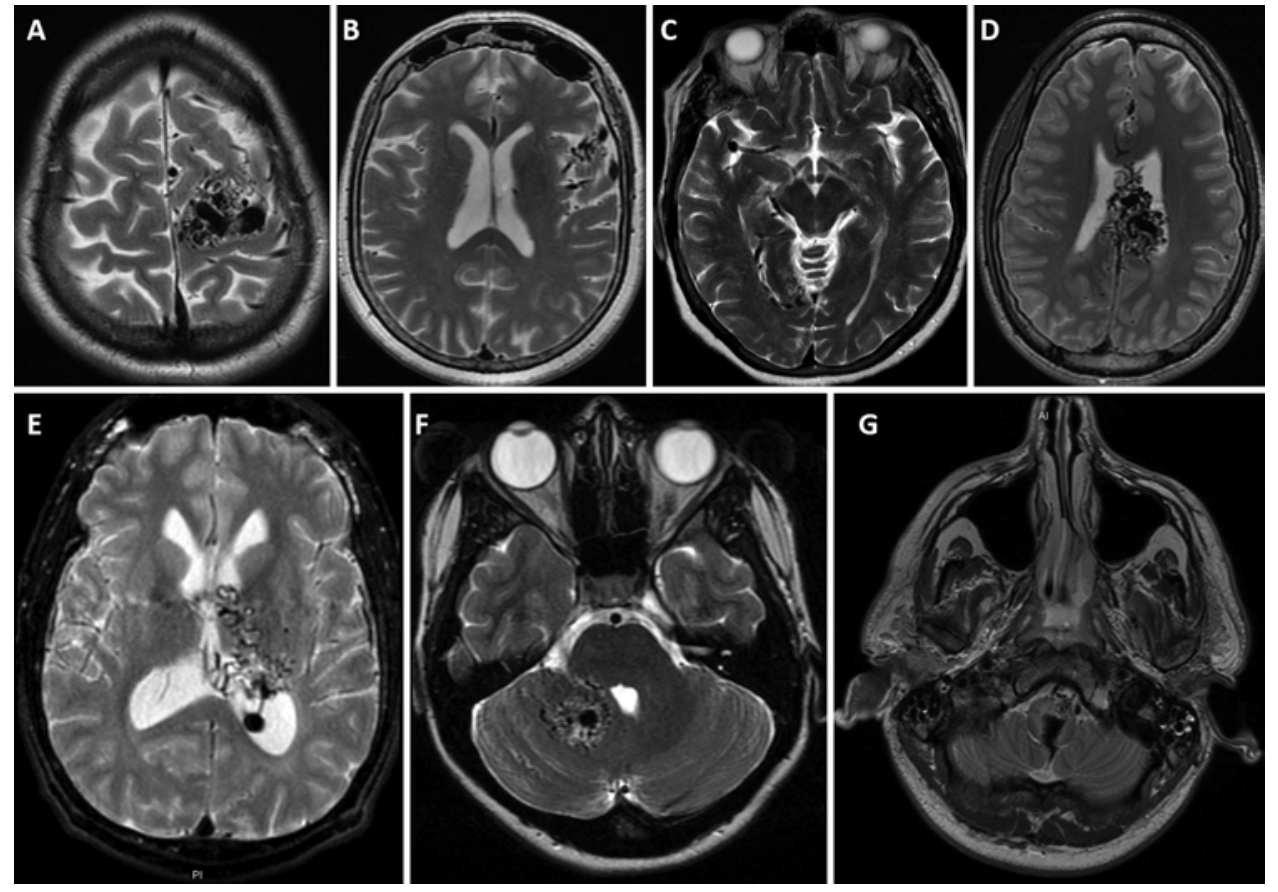

FIG. 1. Images featuring examples of eloquence subtypes: sensorimotor (A), language (B), vision (C), corpus callosum (D), thalamic $(\mathbf{E})$, deep cerebellar nuclei $(\mathbf{F})$, and brainstem $(\mathbf{G})$.

While the majority of these grading scales take brain eloquence into account, none of them differentiate the types of eloquence. One exception may be the radiosurgery-based grading system,,$^{22,23}$ which accounts for AVM location, a surrogate for eloquence type. Thus, a patient with an AVM in the motor strip, for example, may receive the same grade as a patient with an AVM in the optic radiations. Damage to these structures can result in very different neurological deficits with potentially variable impact on overall clinical outcome. There has been some interest in the lesion-to-eloquence distance (LED), ${ }^{11,12}$ but a study assessing the risk of resection in specific eloquence types is lacking. The purpose of this study was to determine how eloquence type affects clinical outcome. We hypothesized that the resection of AVMs that have sensorimotor eloquence can result in worse clinical outcomes than the resection of AVMs that have language, visual, or coordination eloquence.

\section{Methods}

Institutional review board approval was obtained to perform this study, which was a retrospective review of a prospectively collected clinical database of brain AVMs treated with microsurgery by the senior author at the University of California, San Francisco, in the period from August 1997 to March 2017. The only study inclusion criterion was the presence of eloquence as defined by the SM grading scale. Arteriovenous malformations that spanned multiple areas of eloquence $(n=8)$ were excluded. Two AVMs located in the corpus callosum were also excluded. Following exclusions, 241 patients with eloquent AVMs were identified for evaluation, which represents $30 \%$ of the total 804 AVMs resected by the senior author during the study period. Preoperatively, all patients underwent complete neurological examination, and a baseline modified Rankin Scale (mRS) score was assigned. All patients underwent CT scanning, MRI, and catheter angiography. Patients with AVMs in or near motor or sensory cortex also underwent functional MRI (fMRI) and/ or magnetic source imaging (MSI). Patients with AVMs in the language cortex underwent language testing (naming, counting, reading, and verbal fluency tests) conducted by a neuropsychologist. Baseline patient and AVM data were collected by research coordinators. The AVMs were graded using both the SM scale and the Lawton-Young supplementary grading scale. ${ }^{16}$ The following types/locations of eloquence were recorded in the database (Fig. 1): sensorimotor, language, visual, thalamic, internal capsule, basal ganglia, corpus callosum, insular, brainstem, deep cerebellar nuclei, and cerebellar peduncle. Eloquence was determined by radiologists based on preoperative MRI and angiography. For the purposes of comparison in our study, eloquence was grouped as follows: 1) sensorimotor (sensorimotor cortex, thalamus, internal capsule, basal ganglia, and brainstem), 2) visual, 3) language, and 4) coordination (deep cerebellar nuclei and cerebellar peduncle).

An overall treatment strategy for each patient was designed by a multidisciplinary team. Because data were derived from the senior author's surgical database, the overwhelming approach was surgical in nature with the goal of obtaining complete resection with or without supplemental treatments (embolization, radiation). Patients with AVMs less than $10 \mathrm{~mm}$ from the motor or language cortex, as determined by fMRI and/or MSI, and with normal neuropsychological language testing (> 90\% proficiency) 
were selected for intraoperative brain mapping. ${ }^{6}$ Imaging outcome was based on digital subtraction angiography in the vast majority of cases and on MRI in a very small number of cases. Clinical outcome was measured using the mRS. Assessments were performed by trained research coordinators under the supervision of the study neurologist. Our protocol for patients with complete resection involved a follow-up evaluation every 6 months up to 2 years postsurgery. Patients with residual AVM were monitored annually until cure and then 2 years thereafter. Some patients were lost to follow-up. Poor outcome was defined as an mRS score 3-6 at follow-up. Worsening clinical status was defined as an increase in the $\mathrm{mRS}$ score at follow-up compared to the preoperative assessment.

\section{Statistical Analysis}

Patient demographic and clinical data were aggregated in Microsoft Excel (version 16, Microsoft Corp.), and statistical analyses were performed using Stata/SE 15 (StataCorp). Univariate analysis was performed to first assess the unadjusted associations of preoperative risk factors with worsened postoperative mRS score and poor outcomes as primary outcomes. To obtain adjusted risk estimates, clinically relevant variables based on previous studies (age, history of hemorrhage, AVM size, deep drainage, and diffuseness) $)^{16,25}$ were included in multivariate logistic regression models. Types of eloquence were included as a single categorical variable with four values: sensorimotor, visual, language, and coordination. This model adjusted for the log of follow-up time to account for the interval from procedure to outcome assessment; this was included as a confounding variable since patients with a longer follow-up time may have better outcomes with more time to recover from surgery.

We then created another multivariate logistic regression model without types of eloquence as independent variables and compared it to the model with types of eloquence using a likelihood ratio test. All other variables (age, history of hemorrhage, AVM size, deep drainage, diffuseness, log follow-up time) remained the same between the two models. Statistical significance was established at the alpha level of $p=0.05$. Calculations based on the cohort size to detect a $20 \%$ outcome difference for the mRS score change and poor outcome groups resulted in a power of 0.30 and 0.13 , respectively; to detect a $40 \%$ outcome difference, calculations showed a power of 0.81 and 0.38 , respectively.

\section{Results}

\section{Patient and AVM Characteristics}

Two hundred forty-one patients with eloquent brain AVMs were included in this review. Baseline patient and AVM characteristics are displayed in Table 1. Half the patients were female (49.4\%), and the mean age at diagnosis was 33.9 years. Over half (54.4\%) of the patients presented with AVM hemorrhage. The mean AVM size was $2.7 \mathrm{~cm}$, and the majority of AVMs (98.3\%) were $6 \mathrm{~cm}$ or less in size. Nearly half of the AVMs had deep venous drainage (45.6\%), and a minority were diffuse $(17.0 \%)$. The most common SM grade was III (46.1\%), and the most common
TABLE 1. Baseline patient and AVM characteristics

\begin{tabular}{|c|c|}
\hline Variable & No. \\
\hline No. of patients & 241 \\
\hline Mean age in yrs & $33.9 \pm 16.1$ \\
\hline \multicolumn{2}{|l|}{ Age group } \\
\hline Under 20 yrs & $56(23.2)$ \\
\hline $20-40$ yrs & $99(41.1)$ \\
\hline Over 40 yrs & $86(35.7)$ \\
\hline \multicolumn{2}{|l|}{ Sex } \\
\hline$F$ & $119(49.4)$ \\
\hline $\mathrm{M}$ & $122(50.6)$ \\
\hline Mean AVM size in $\mathrm{cm}$ & $2.7 \pm 1.4$ \\
\hline \multicolumn{2}{|l|}{ AVM size } \\
\hline Under $3 \mathrm{~cm}$ & $141(58.5)$ \\
\hline $3-6 \mathrm{~cm}$ & $96(39.8)$ \\
\hline Over $6 \mathrm{~cm}$ & $4(1.7)$ \\
\hline Hemorrhage & $131(54.4)$ \\
\hline Deep drainage & $110(45.6)$ \\
\hline Diffuseness & $41(17.0)$ \\
\hline Mean SM grade & $2.9 \pm 0.8$ \\
\hline \multicolumn{2}{|l|}{ SM grade } \\
\hline II & $80(33.2)$ \\
\hline III & $111(46.1)$ \\
\hline IV & $47(19.5)$ \\
\hline V & $3(1.2)$ \\
\hline Mean supplemented grade & $5.7 \pm 1.2$ \\
\hline \multicolumn{2}{|l|}{ Supplemented grade } \\
\hline 3 & $5(2.1)$ \\
\hline 4 & $31(12.9)$ \\
\hline 5 & $67(27.8)$ \\
\hline 6 & $84(34.9)$ \\
\hline 7 & $38(15.8)$ \\
\hline 8 & $11(4.6)$ \\
\hline 9 & $5(2.1)$ \\
\hline \multicolumn{2}{|l|}{ AVM location/eloquence } \\
\hline Sensorimotor eloquence & $111(46.1)$ \\
\hline Sensorimotor cortex & $77(32.0)$ \\
\hline Internal capsule & $2(0.8)$ \\
\hline Basal ganglia & $6(2.5)$ \\
\hline Thalamus & $13(5.4)$ \\
\hline Brainstem & $13(5.4)$ \\
\hline Visual eloquence & $65(27.0)$ \\
\hline Language eloquence & $53(22.0)$ \\
\hline Coordination eloquence & $12(5.0)$ \\
\hline Cerebellar peduncle & $8(3.3)$ \\
\hline Deep cerebellar nuclei & $4(1.7)$ \\
\hline
\end{tabular}

Values are expressed as the mean \pm standard deviation or as the number of patients (\%). 
TABLE 2. Treatment and outcome information

\begin{tabular}{lc}
\hline \multicolumn{1}{c}{ Variable } & No. $(\%)$ \\
\hline No. of patients & 241 \\
\hline Treatment & $79(32.8)$ \\
\hline Surgery alone & $125(51.9)$ \\
\hline Surgery \& embolization & $19(7.9)$ \\
\hline Surgery \& radiosurgery & $18(7.5)$ \\
\hline Surgery, embolization, \& radiosurgery & $24(10.0)$ \\
\hline Complications & $13(5.4)$ \\
\hline Hemorrhagic & $5(2.1)$ \\
\hline Ischemic & $6(2.5)$ \\
\hline Infectious & $201(83.4)$ \\
\hline mRS score at last FU & $32(13.3)$ \\
\hline $0-2$ & $8(3.3)$ \\
\hline $3-5$ & $106(44.0)$ \\
\hline 6 & $66(27.4)$ \\
\hline Change in mRS score & $69(28.6)$ \\
\hline Improved & 24 \\
\hline Stable
\end{tabular}

$\mathrm{FU}=$ follow-up.

supplemented grade was $6(34.9 \%)$. The most common eloquence type was sensorimotor (46.1\%), followed by visual $(27.0 \%)$ and language (22.0\%). Specifically, among cortical sensorimotor AVMs $(n=77)$, there were 29 in the motor cortex, 31 in the sensory cortex, and 17 spanning both cortices.

\section{Treatment and Outcome}

Treatment and outcome information is displayed in Table 2 . All patients were treated surgically, with $32.8 \%$ having microsurgery only, $51.9 \%$ having microsurgery with preoperative embolization, $7.9 \%$ having microsurgery and radiosurgery, and $7.5 \%$ undergoing all three treatment modalities. Of the AVMs with sensorimotor eloquence, motor mapping was performed in 9 cortically based cases $(8.1 \%)$ and 1 brainstem case $(0.9 \%)$. Of the AVMs with language eloquence, awake speech mapping was performed in 7 cases (13.2\%). Complications occurred in 24 patients $(10 \%)$. The vast majority of patients $(97 \%)$ underwent postoperative angiography. Eight patients without a postoperative angiogram had an MR image. Complete AVM resection was achieved in $86.7 \%$ of patients. The average time to last follow-up was 24 months. At the last followup, $83.4 \%$ had a good clinical outcome (mRS score 0-2), $16.6 \%$ had a poor outcome (mRS 3-6), and 3.3\% were deceased (mRS score 6). Compared to the preoperative state, $44.0 \%$ of patients had an improved mRS score, $27.4 \%$ had a stable score, and $28.6 \%$ had a worse score.

\section{Impact of Eloquence on Clinical Outcome}

There was no statistically significant difference in the baseline patient and AVM characteristics among the different subtypes of eloquence (Table 3). Complications were more common in AVM cases with coordination eloquence $(\mathrm{p}=0.008)$.

In our univariate analysis (Table 4), AVM size ( $\mathrm{p}=$ $0.045)$, preoperative hemorrhage $(\mathrm{p}=0.003)$, and supplemented grade $(\mathrm{p}=0.003)$ were all associated with worsening clinical status. The SM grade $(\mathrm{p}=0.037)$ and eloquence subtype $(p=0.017)$ were both associated with a poor outcome. Among the patients with visual eloquence, $4.6 \%$ had a poor outcome. In comparison, $22.5 \%$ of those

TABLE 3. Comparison of eloquence subtypes

\begin{tabular}{|c|c|c|c|c|c|}
\hline Variable & Sensorimotor $(n=111)$ & Visual $(n=65)$ & Language $(n=53)$ & Coordination $(n=12)$ & $\mathrm{p}$ Value \\
\hline Age (yrs) & $33.4 \pm 16.6$ & $31.0 \pm 14.9$ & $36.5 \pm 15.3$ & $41.3 \pm 19.8$ & 0.531 \\
\hline Male sex (\%) & 49.6 & 52.3 & 50.9 & 50.0 & 0.988 \\
\hline AVM size $(\mathrm{cm})$ & $2.7 \pm 1.3$ & $2.8 \pm 1.5$ & $2.8 \pm 1.3$ & $2.7 \pm 1.6$ & 0.495 \\
\hline Deep drainage (\%) & 49.6 & 46.2 & 32.1 & 66.7 & 0.080 \\
\hline Hemorrhage (\%) & 58.6 & 55.4 & 43.4 & 58.3 & 0.326 \\
\hline Diffuseness (\%) & 16.2 & 15.4 & 15.1 & 41.7 & 0.140 \\
\hline Mean SM grade & $2.9 \pm 0.7$ & $2.9 \pm 0.8$ & $2.8 \pm 0.8$ & $3.3 \pm 0.8$ & 0.487 \\
\hline Mean supplemental grade & $5.6 \pm 1.1$ & $5.7 \pm 1.3$ & $5.8 \pm 1.3$ & $6.4 \pm 1.2$ & 0.295 \\
\hline Treatment (\%) & & & & & 0.091 \\
\hline Surgery alone & 34.2 & 30.8 & 30.2 & 41.7 & \\
\hline Surgery \& embolization & 42.3 & 60.0 & 60.4 & 58.3 & \\
\hline Surgery \& radiosurgery & 11.7 & 3.1 & 7.6 & 0.0 & \\
\hline Surgery, embolization, \& radiosurgery & 11.7 & 6.2 & 1.9 & 0.0 & \\
\hline Complete resection (\%) & 84.7 & 90.8 & 84.9 & 91.7 & 0.630 \\
\hline Complications (\%) & 12.6 & 0.0 & 13.2 & 25.0 & 0.008 \\
\hline
\end{tabular}

$\mathrm{n}=$ number of cases.

Boldface type indicates statistical significance. 
TABLE 4. Univariate analysis of predictors of postoperative $m R S$ score increase and poor outcome

\begin{tabular}{|c|c|c|c|c|c|c|}
\hline Variable & $\begin{array}{c}\text { No mRS Score } \\
\text { Increase }\end{array}$ & $\begin{array}{l}\text { mRS Score } \\
\text { Increase }\end{array}$ & $\begin{array}{c}p \\
\text { Value }\end{array}$ & $\begin{array}{l}\text { Good Outcome } \\
\text { (mRS score 0-2) }\end{array}$ & $\begin{array}{l}\text { Poor Outcome } \\
\text { (mRS score 3-6) }\end{array}$ & $\begin{array}{c}\mathrm{p} \\
\text { Value }\end{array}$ \\
\hline No. of patients & 172 & 69 & & 201 & 40 & \\
\hline Age group, no. of patients (\%) & & & 0.061 & & & 0.610 \\
\hline Under 20 yrs & $45(80.4)$ & $11(19.6)$ & & $48(85.7)$ & $8(14.3)$ & \\
\hline $20-40$ yrs & $73(73.7)$ & $26(26.3)$ & & $84(84.8)$ & $15(15.2)$ & \\
\hline Over 40 yrs & $54(62.8)$ & $32(37.2)$ & & $69(80.2)$ & $17(19.8)$ & \\
\hline AVM size, no. of patients (\%) & & & 0.045 & & & 0.163 \\
\hline Under $3 \mathrm{~cm}$ & $109(77.3)$ & $32(22.7)$ & & $123(87.2)$ & $18(12.8)$ & \\
\hline $3-6 \mathrm{~cm}$ & $61(63.5)$ & $35(36.5)$ & & $75(78.1)$ & $21(21.9)$ & \\
\hline Over $6 \mathrm{~cm}$ & $2(50.0)$ & $2(50.0)$ & & $3(75.0)$ & $1(25.0)$ & \\
\hline Hemorrhage, no. of patients (\%) & $104(79.4)$ & $27(20.6)$ & 0.003 & $106(80.9)$ & $25(19.1)$ & 0.258 \\
\hline Deep drainage, no. of patients (\%) & $81(73.6)$ & $29(26.4)$ & 0.476 & $87(79.1)$ & $23(20.9)$ & 0.099 \\
\hline Diffuseness, no. of patients (\%) & $28(68.3)$ & $13(31.7)$ & 0.632 & $31(75.6)$ & $10(24.4)$ & 0.141 \\
\hline SM grade, no. of patients (\%) & & & 0.347 & & & 0.037 \\
\hline II & $61(76.3)$ & $19(23.8)$ & & $73(91.3)$ & $7(8.8)$ & \\
\hline III & $77(69.4)$ & $34(30.6)$ & & $91(82.0)$ & $20(18.0)$ & \\
\hline IV & $33(70.2)$ & $14(29.8)$ & & $34(72.3)$ & $13(27.7)$ & \\
\hline V & $1(33.3)$ & $2(66.7)$ & & $3(100.0)$ & $0(0.0)$ & \\
\hline Supplemented grade (\%) & & & 0.003 & & & 0.242 \\
\hline 3 & $5(100.0)$ & $0(0.0)$ & & $5(100.0)$ & $0(0.0)$ & \\
\hline 4 & 27 (87.1) & $4(12.9)$ & & $27(87.1)$ & $4(12.9)$ & \\
\hline 5 & $52(77.6)$ & $15(22.4)$ & & $58(86.6)$ & $9(13.4)$ & \\
\hline 6 & $61(72.6)$ & $23(27.4)$ & & $71(84.5)$ & $13(15.5)$ & \\
\hline 7 & $20(52.6)$ & $18(47.4)$ & & $27(71.1)$ & $11(28.9)$ & \\
\hline 8 & $4(36.4)$ & $7(63.6)$ & & $8(72.7)$ & $3(27.3)$ & \\
\hline 9 & $3(60.0)$ & $2(40.0)$ & & $5(100.0)$ & $0(0.0)$ & \\
\hline Eloquence subtype, no. of patients (\%) & & & 0.685 & & & 0.017 \\
\hline Sensorimotor* & $82(73.9)$ & $29(26.1)$ & & $86(77.5)$ & $25(22.5)$ & \\
\hline Visual & $45(69.2)$ & $20(30.8)$ & & $62(95.4)$ & $3(4.6)$ & \\
\hline Language & $38(71.7)$ & $15(28.3)$ & & $44(83.0)$ & $9(17.0)$ & \\
\hline Coordination $†$ & $7(58.3)$ & $5(41.7)$ & & $9(75.0)$ & $3(25.0)$ & \\
\hline
\end{tabular}

Boldface type indicates statistical significance.

* Subtype includes sensorimotor cortex, internal capsule, basal ganglia, thalamus, and brainstem.

† Subtype includes deep cerebellar nuclei and cerebellar peduncle.

with sensorimotor eloquence, $17 \%$ of those with language eloquence, and $25 \%$ of those with coordination eloquence had poor outcomes. In a subgroup analysis of cortical motor AVMs $(\mathrm{n}=29)$ compared to cortical sensory AVMs (n $=31$ ), there were no statistically significant differences in either worsening clinical status $(\mathrm{p}=0.185)$ or poor outcome $(\mathrm{p}=0.655)$.

In our multivariate analysis (Table 5), older age (OR $1.25, \mathrm{p}=0.012)$, larger AVM size (OR 1.3, $\mathrm{p}=0.022)$, and preoperative hemorrhage (OR $0.46, p=0.012)$ were all associated with worsening clinical status. Similarly, older age (OR 1.31, $\mathrm{p}=0.016)$ and larger AVM size (OR 1.37, $\mathrm{p}=0.034)$ were associated with a poor outcome. In comparison to visual eloquence, both sensorimotor (OR 7.4, $\mathrm{p}$ $=0.004)$ and language $(\mathrm{OR} 6.5, \mathrm{p}=0.015)$ eloquence were associated with a poor outcome. While coordination elo- quence had a higher risk of a poor outcome, this relationship was not statistically significant (OR 4.5, $\mathrm{p}=0.145)$.

\section{Discussion}

\section{Main Findings}

Our study confirms our hypothesis that AVM eloquence subtype does, in fact, have an influence on outcome following resection. We hypothesized that sensorimotor eloquence would have a greater association with poor outcome than the other eloquence subtypes. We found that both sensorimotor and language eloquence have associations with poor outcome in comparison to visual eloquence. Our results suggest that although eloquent AVMs of the sensorimotor or language cortex may receive the same SM or supplemented grade as an otherwise equiva- 
TABLE 5. Multivariate analysis of predictors of postoperative mRS score increase and poor outcome*

\begin{tabular}{|c|c|c|c|c|}
\hline \multirow[b]{2}{*}{ Variable } & \multicolumn{2}{|c|}{ mRS Increase } & \multicolumn{2}{|c|}{ Poor Outcome (mRS score 3-6) } \\
\hline & OR $(95 \% \mathrm{Cl})$ & p Value & OR $(95 \% \mathrm{Cl})$ & p Value \\
\hline \multicolumn{5}{|l|}{ Eloquence } \\
\hline Visual & 1.000 & Reference & 1.000 & Reference \\
\hline Sensorimotort & $0.734(0.356,1.511)$ & 0.401 & $7.393(1.895,28.843)$ & 0.004 \\
\hline Language & $0.686(0.291,1.616)$ & 0.389 & $6.495(1.438,29.346)$ & 0.015 \\
\hline Coordination $\ddagger$ & $1.272(0.323,5.007)$ & 0.731 & $4.543(0.592,34.870)$ & 0.145 \\
\hline Older age (by decade) & $1.250(1.060,1.460)$ & 0.012 & $1.310(1.060,1.570)$ & 0.016 \\
\hline Larger AVM size (per cm) & $1.307(1.040,1.642)$ & 0.022 & $1.372(1.024,1.837)$ & 0.034 \\
\hline Deep drainage & $0.858(0.457,1.614)$ & 0.636 & $1.814(0.801,4.108)$ & 0.153 \\
\hline Diffuseness & $1.081(0.485,2.407)$ & 0.849 & $2.127(0.811,5.577)$ & 0.125 \\
\hline Preop hemorrhage & $0.459(0.249,0.843)$ & 0.012 & $1.98(0.865,4.533)$ & 0.106 \\
\hline $\log (\mathrm{FU})$ & $0.611(0.395,0.946)$ & 0.027 & $0.273(0.159,0.470)$ & $<0.001$ \\
\hline
\end{tabular}

Boldface type indicates statistical significance.

${ }^{*}$ Multivariate analysis is a multiple logistic regression model adjusting for time between surgery and last mRS score assessment. † Subtype includes sensorimotor cortex, internal capsule, basal ganglia, thalamus, and brainstem.

$\ddagger$ Subtype includes deep cerebellar nuclei and cerebellar peduncle.

lent AVM of the visual cortex, the risk of a poor outcome may be higher with the former.

In addition, we found that an older patient age and a larger AVM size both have associations with worsening clinical status and poor outcome, according to LawtonYoung and SM grading. Preoperative hemorrhage was protective against a worsening clinical status, which likely reflects the damage already done by the hemorrhage, not the treatment. This factor has been explored in detail in the supplemented grading system. Our results regarding coordination eloquence are likely difficult to interpret given the small number of patients and higher rate of complications in this subgroup.

\section{Classifications of AVM}

Microsurgical resection of brain AVM requires careful patient selection to avoid postoperative surgical complications and poor neurological outcomes. The wide heterogeneity of AVMs with respect to their size, anatomy, location, and patient characteristics further complicates the surgical decision-making process. ${ }^{7,9,14}$ In recent decades, numerous classification schemes have been developed to predict the risks of AVM treatment. $4,5,16,19,22,23,25,26,28,30$ Grading systems can be helpful by inviting the educated clinical gestalt of operative risk by a surgeon to be compared to an objective number that summarizes known risk factors based on large sample sizes.

First introduced in 1986, the SM grading system-a five-point scheme based on AVM size, eloquence, and deep venous drainage-is accepted as the predominant scale in predicting postoperative outcomes. ${ }^{25}$ As research elucidated more factors contributing to AVM surgical risks, 3,15,24,27 several improvements have been proposed to increase the predictive value of the SM grading system and refine surgical patient selection. ${ }^{26}$ One such augmentation of the SM system was the Lawton-Young supplementary grading system. ${ }^{16}$ This supplementary system is analogous to the fivetier model of the SM system and assigns points to three additional categories: patient age, history of hemorrhage, and AVM compactness. The combined SM and supplementary grading system (or supplemented SM grade) has been shown to accurately predict neurological outcomes after AVM surgery in a multicenter cohort study of 1009 patients. ${ }^{13}$ Our multivariate analysis, which found associations between older age, larger AVM size, or unruptured AVM status and worsening clinical status after treatment, is consistent with the previous SM and Lawton-Young supplementary grading scales. Alternative AVM classification schemes have included factors such as the Hunt and Hess grade ${ }^{8} \mathrm{AVM}$ volume,${ }^{22}$ feeding artery supply, ${ }^{8,21}$ and other hemodynamic factors. ${ }^{21}$

Some authors have broken the SM grades into components to better understand which AVMs within a given grade harbor more or less surgical risk. For instance, Lawton demonstrated that among grade III AVMs, the S1V1E1 subtype behaved similarly to grade II AVMs with a lower surgical risk, whereas the S2V0E1 subtype behaved more like high-grade AVMs with a higher surgical risk. ${ }^{14}$ Pandey et al. demonstrated similar results in that small, grade III AVM cases (S1V1E1) had the lowest risk of developing new neurological deficits. ${ }^{20}$ Together, these studies suggest that size may be the most important factor among grade III AVMs. Most recently, Hung et al. performed the same analysis for grade II AVMs and found that the S2V0E0 subtype had the best outcome, whereas the S1V1E0 subtype had the worst outcome, ${ }^{9}$ suggesting that deep venous drainage portends a worse outcome than eloquence for grade II AVMs. Even with numerous grading scales in hand, it has been shown in an online survey that there is wide variation in clinicians' opinions on which patient and/or AVM characteristics are most important for decisions regarding treatment or trial enrollment. ${ }^{2}$

\section{Eloquence}

Most classification systems recognize eloquence of the brain region adjacent to the nidus as an important factor 
and incorporate it. However, none of the grading scales differentiate the various types of eloquence: motor, speech, coordination, sensation, and vision. While the modified Pittsburgh radiosurgery-based AVM grading system accounts for location, ${ }^{22}$ the assigned points do not differ between eloquence types specifically.

One element of eloquence that has been studied is lesion-to-eloquence distance (LED) ${ }^{10-12,18}$ Jiao et al. recently proposed a modified grading scale in which the LED is taken into account. ${ }^{12}$ All patients in their study underwent fMRI and diffusion tensor imaging (DTI) to determine exactly where areas of eloquence were located. An LED of $4.95 \mathrm{~mm}$ was the cutoff for a worsened mRS score. These findings, together with our own, suggest that more extensive functional imaging and/or tractography will be necessary to refine eloquence grading beyond what can be done with angiography and MRI. The authors evaluated a number of different grading scales based on different combinations of patient and AVM factors and found that their so-called HDVL scale-which includes hemorrhagic presentation, diffuseness, deep venous drainage, and LED-outperformed other scales and was significantly more predictive than the SM scale. This HDVL scale can be viewed as a variation of the supplemented SM grading system, which combines SM and Lawton-Young grades, with the addition of LED to measure eloquence.

Finally, certain techniques can be employed to better handle AVMs that reside within eloquent tissue. Gabarrós et al. reported on the use of language and motor mapping in a number of patients from the same database. ${ }^{6}$ The practice was used infrequently (2.8\%) but allowed the surgeon to identify functional cortex, guide dissection through normal cortex to the nidus, and limit the extent of resection in certain cases. Arteriovenous malformations can be completely dissected with occlusion of the arterial supply and then left in situ to preserve venous drainage and limit dissection in eloquent tissue. These authors concluded that indications for speech and motor mapping include preoperative functional imaging that identifies the language/motor cortex adjacent to the AVM, larger AVMs with higher SM grades, and patients presenting with unruptured AVMs without deficits. In our study, mapping was used approximately $10 \%$ of the time among AVMs with sensorimotor or language eloquence.

Our present study demonstrates that eloquence subtype does, in fact, affect outcome and that AVMs with sensorimotor and language eloquence have a greater association with a poor outcome. This nuance in AVM eloquence demands careful consideration before deciding on microsurgical intervention, especially when numerical grading systems produce a score near the borderline between operative and nonoperative management.

\section{Study Limitations}

First, the database only includes surgically treated AVMs. Difficult-to-treat eloquent AVMs with an anticipated poor outcome with resection were almost certainly selected out. Conversely, some patients with difficultto-treat eloquent AVMs and anticipated increases in the mRS score knowingly opted in for the sake of curative AVM resection. For example, some patients with AVMs in visual cortex or sensory cortex decided to proceed with surgery because the expected visual field deficits or numbness were acceptable and preferable to the risks of AVM rupture. Therefore, surgeon and patient selection biases impact the surgical results.

Second, because a single surgeon operated on all of the AVMs, the findings may not generalize to other surgeons. Similarly, the judicious use of speech and motor mapping by the senior author may have prevented devastating deficits and ultimately impacted clinical outcomes. Third, assigning eloquence based on anatomical location may be flawed methodologically. For instance, it has been shown that eloquence can shift or translocate in the presence of $\mathrm{AVMs}^{17,29}$ and, as discussed above, the distance from the AVM to eloquence may be the more important factor.

\section{Conclusions}

The majority of AVMs are treated with multimodality therapy. Unlike visual eloquence, sensorimotor and language eloquence were associated with worse clinical outcomes after the resection of eloquent AVMs. This nuance in AVM eloquence demands consideration before deciding on microsurgical intervention, especially when numerical grading systems produce a score near the borderline between operative and nonoperative management.

\section{References}

1. Banks JL, Marotta CA: Outcomes validity and reliability of the modified Rankin scale: implications for stroke clinical trials: a literature review and synthesis. Stroke 38:10911096, 2007

2. Cockroft KM, Chang KE, Lehman EB, Harbaugh RE: AVM Management Equipoise Survey: physician opinions regarding the management of brain arteriovenous malformations. J Neurointerv Surg 6:748-753, 2014

3. Du R, Keyoung HM, Dowd CF, Young WL, Lawton MT: The effects of diffuseness and deep perforating artery supply on outcomes after microsurgical resection of brain arteriovenous malformations. Neurosurgery 60:638-648, 2007

4. Dumont TM, Kan P, Snyder KV, Hopkins LN, Siddiqui AH, Levy EI: A proposed grading system for endovascular treatment of cerebral arteriovenous malformations: Buffalo score. Surg Neurol Int 6:3, 2015

5. Feliciano CE, de León-Berra R, Hernández-Gaitán MS, Rodríguez-Mercado R: A proposal for a new arteriovenous malformation grading scale for neuroendovascular procedures and literature review. P R Health Sci J 29:117-120, 2010

6. Gabarrós A, Young WL, McDermott MW, Lawton MT: Language and motor mapping during resection of brain arteriovenous malformations: indications, feasibility, and utility. Neurosurgery 68:744-752, 2011

7. Gross BA, Du R: Natural history of cerebral arteriovenous malformations: a meta-analysis. J Neurosurg 118:437-443, 2013

8. Höllerhage HG, Dewenter KM, Dietz H: Grading of supratentorial arteriovenous malformations on the basis of multivariate analysis of prognostic factors. Acta Neurochir (Wien) 117:129-134, 1992

9. Hung AL, Yang W, Westbroek EM, Garzon-Muvdi T, Caplan JM, Braileanu M, et al: Differences in functional outcome across subtypes with Spetzler-Martin grade II arteriovenous malformations. Neurosurgery 81:441-449, 2017

10. Jiao Y, Lin F, Wu J, Li H, Chen X, Li Z, et al: Brain arteriovenous malformations located in premotor cortex: surgical 
outcomes and risk factors for postoperative neurologic deficits. World Neurosurg 105:432-440, 2017

11. Jiao Y, Lin F, Wu J, Li H, Wang L, Jin Z, et al: Lesion-toeloquent fiber distance is a crucial risk factor in presurgical evaluation of arteriovenous malformations in the temporooccipital junction. World Neurosurg 93:355-364, 2016

12. Jiao Y, Lin F, Wu J, Li H, Wang L, Jin Z, et al: A supplementary grading scale combining lesion-to-eloquence distance for predicting surgical outcomes of patients with brain arteriovenous malformations. J Neurosurg 128:530-540, 2018

13. Kim H, Abla AA, Nelson J, McCulloch CE, Bervini D, Morgan MK, et al: Validation of the supplemented Spetzler-Martin grading system for brain arteriovenous malformations in a multicenter cohort of 1009 surgical patients. Neurosurgery 76:25-33, 2015

14. Lawton MT: Spetzler-Martin Grade III arteriovenous malformations: surgical results and a modification of the grading scale. Neurosurgery 52:740-749, 2003

15. Lawton MT, Du R, Tran MN, Achrol AS, McCulloch CE, Johnston SC, et al: Effect of presenting hemorrhage on outcome after microsurgical resection of brain arteriovenous malformations. Neurosurgery 56:485-493, 2005

16. Lawton MT, Kim H, McCulloch CE, Mikhak B, Young WL: A supplementary grading scale for selecting patients with brain arteriovenous malformations for surgery. Neurosurgery 66:702-713, 2010

17. Lee L, Sitoh YY, Ng I, Ng WH: Cortical reorganization of motor functional areas in cerebral arteriovenous malformations. J Clin Neurosci 20:649-653, 2013

18. Lin F, Zhao B, Wu J, Wang L, Jin Z, Cao Y, et al: Risk factors for worsened muscle strength after the surgical treatment of arteriovenous malformations of the eloquent motor area. $\mathbf{J}$ Neurosurg 125:289-298, 2016

19. Lopes DK, Moftakhar R, Straus D, Munich SA, Chaus F, Kaszuba MC: Arteriovenous malformation embocure score: AVMES. J Neurointerv Surg 8:685-691, 2016

20. Pandey P, Marks MP, Harraher CD, Westbroek EM, Chang SD, Do HM, et al: Multimodality management of SpetzlerMartin Grade III arteriovenous malformations. J Neurosurg 116:1279-1288, 2012

21. Pertuiset B, Ancri D, Kinuta Y, Haisa T, Bordi L, Lin C, et al: Classification of supratentorial arteriovenous malformations. A score system for evaluation of operability and surgical strategy based on an analysis of 66 cases. Acta Neurochir (Wien) 110:6-16, 1991

22. Pollock BE, Flickinger JC: Modification of the radiosurgerybased arteriovenous malformation grading system. Neurosurgery 63:239-243, 2008

23. Pollock BE, Flickinger JC: A proposed radiosurgery-based grading system for arteriovenous malformations. J Neurosurg 96:79-85, 2002
24. Sanchez-Mejia RO, Chennupati SK, Gupta N, Fullerton H, Young WL, Lawton MT: Superior outcomes in children compared with adults after microsurgical resection of brain arteriovenous malformations. J Neurosurg 105 (2 Suppl):82-87, 2006

25. Spetzler RF, Martin NA: A proposed grading system for arteriovenous malformations. J Neurosurg 65:476-483, 1986

26. Spetzler RF, Ponce FA: A 3-tier classification of cerebral arteriovenous malformations. Clinical article. J Neurosurg 114:842-849, 2011

27. Stapf C, Mast H, Sciacca RR, Choi JH, Khaw AV, Connolly ES, et al: Predictors of hemorrhage in patients with untreated brain arteriovenous malformation. Neurology 66:1350-1355, 2006

28. Starke RM, Yen CP, Ding D, Sheehan JP: A practical grading scale for predicting outcome after radiosurgery for arteriovenous malformations: analysis of 1012 treated patients. J Neurosurg 119:981-987, 2013

29. Vates GE, Lawton MT, Wilson CB, McDermott MW, Halbach VV, Roberts TP, et al: Magnetic source imaging demonstrates altered cortical distribution of function in patients with arteriovenous malformations. Neurosurgery 51:614627,2002

30. Wegner RE, Oysul K, Pollock BE, Sirin S, Kondziolka D, Niranjan A, et al: A modified radiosurgery-based arteriovenous malformation grading scale and its correlation with outcomes. Int J Radiat Oncol Biol Phys 79:1147-1150, 2011

\section{Disclosures}

The authors report no conflict of interest concerning the materials or methods used in this study or the findings specified in this paper.

\section{Author Contributions}

Conception and design: all authors. Acquisition of data: all authors. Analysis and interpretation of data: all authors. Drafting the article: Mascitelli, Yoon, Cole. Critically revising the article: all authors. Reviewed submitted version of manuscript: all authors. Approved the final version of the manuscript on behalf of all authors: Lawton. Statistical analysis: Yoon, Cole, Kim. Administrative/technical/material support: Lawton, Kim. Study supervision: Lawton, Mascitelli.

\section{Correspondence}

Michael T. Lawton: Barrow Neurological Institute, Phoenix, AZ. michael.lawton@barrowbrainandspine.com. 